\title{
SOLID STATE ION EXCHANGE REACTIONS OF Co WITH ZEOLITES
}

\author{
A. Jentys, A. Lugstein and II. Vinek \\ Institut für Physikalische Chemie, TU Wien, Getreidemarkt 9, 1060 Wien, Austria
}

\begin{abstract}
Co cations were introduced into ZSM5 and faujasite type zeolites by solid state ion exchange. On both types of zeolites the solid state reaction led to an exchange of all protons. On ZSM5 one proton was exchanged with one $\mathrm{Co}^{2+}$ cation, while on the faujasite samples two protons were exchanged with one $\mathrm{Co}^{2+}$ cation. After the incorporation of cobalt two new Lewis acid sites were observed on the CoZSM5 and CoY samples.
\end{abstract}

PACS numbers: 82.65.Jv, 71.20.Be, 71.20.Ps, 81.20.Fw, 61.10.Ht, 77.84.Bw

\section{Introduction}

Bifunctional catalysts are extending the utilization of zeolites from applications based on their acidic properties (e.g., cracking or isomerization), to reactions such as hydrocracking [1] and deep hydrotreating [2] for which a hydrogenation function is indispensable. In these reactions mostly the role of the transition metal cations in the molecular sieve is to provide enough hydrogen to keep the acid sites clean and/or to establish the olefin/paraffin equilibrium. Lately, transition metal containing zeolites are used in increasing extent to ensure hydrogenation of aromatics and unsaturated components in situations when a high sulfur concentration of the reactants limits the use of traditional noble metal catalysts [3].

Transition metals can be introduced into zeolites via different routes, i.e., decomposition of volatile metal organic complexes [4], direct synthesis [5], impregnation [6] and ion exchange [7].

In this paper we describe the introduction of $\mathrm{Co}^{2+}$ cations into faujasite and ZSM5 by solid state ion exchange methods and their characterization by X-ray absorption spectroscopy. The role of the concentration of ion exchange sites upon the density and location of the exchanged cations and the influence of pore diameter is discussed.

\section{Experimental}

\subsection{Ion exchange}

The zeolites used as starting material had a $\mathrm{Si} / \mathrm{Al}$ ratio of 26 and 2.5 for ZSM5 and faujasite, respectively. The solid state ion exchange reaction was carried out by grinding the zeolite together with $\mathrm{CoCl}_{2} \cdot 6 \mathrm{H}_{2} \mathrm{O}$ and heating the mixture in $\mathrm{He}$ atmosphere with a heating rate of $2 \mathrm{~K} \cdot \mathrm{min}^{-1}$ to a final temperature of 
$773 \mathrm{~K}$ for ZSM5 and to $473 \mathrm{~K}$ for faujasite for 8 hours. These temperatures were chosen in order to minimize the amount of $\mathrm{Al}^{3+}$ removed from the zeolite lattice by dealumination reactions. The amount of $\mathrm{CoCl}_{2}$ was selected in order to achieve the desired $\mathrm{Co}^{2+} / \mathrm{Al}^{3+}$ ratio in the final material. After ion exchange the samples were washed repeatedly with water until anions could not be detected in the solution and dried at $373 \mathrm{~K}$.

\subsection{Concentration of acid sites}

The concentration and strength of the acid sites were determined by temperature programmed desorption of $\mathrm{NH}_{3}$. The samples were activated in vacuum at $773 \mathrm{~K}$ for 60 minutes (ZSM5) or at $673 \mathrm{~K}$ for 15 minutes (faujasite). $\mathrm{NH}_{3}$ was adsorbed with a partial pressure of 10 mbar at ambient temperature for 15 minutes. After evacuation, temperature programmed desorption (t.p.d.) was carried out using a temperature increment of $10 \mathrm{~K} \cdot \mathrm{min}^{-1}$, detecting the desorbing molecules with a quadrupole mass spectrometer. The stoichiometry of the ion exchange reaction was determined from the $\mathrm{Co}^{2+}$ concentration, obtained from chemical analysis and the concentration of Brønsted acid sites present after the ion exchange reaction.

\section{3. $X$-ray absorption spectra}

The X-ray absorption spectra were measured at the NSLS (National Synchrotron Light Source, National Brookhaven Laboratory, Upton NY) at the beamline X23A2 in transmission mode using a stepwise moving monochromator equipped with $\mathrm{Si}(311)$ crystals. The samples were prepared as self-supporting wavers and placed inside a cell which allows to measure X-ray absorption spectra in situ during the sample pretreatment. The weight of the samples was selected to achieve a total absorption of less than $\mu x=2.0$. X-ray absorption spectra were measured at liquid nitrogen temperature after drying the samples in $\mathrm{He}$ at $373 \mathrm{~K}$. The Co $K$ absorption edges were aligned with that of bulk Co and normalized to the mass areal loading of the samples. For the analysis of the EXAFS the background was removed using a polynomial baseline approximation and the contributions of the first coordination shell were isolated by a Fourier transformation of the $k^{2}$ weighted oscillations $\left(k=3-18 \AA^{-1}\right)$. The structural parameters were determined under the assumption of single scattering and plane waves using phase shift and amplitude functions obtained from experimental data of Co reference compounds. The structural integrity of the zeolites throughout all procedures was verified by $\mathrm{X}$-ray diffraction (XRD) measurements.

\section{Results}

The $\mathrm{NH}_{3}$ t.p.d. of the samples after ion exchange are compiled in Fig. 1. The concentration of strong Brønsted acid sites as a function of the $\mathrm{Co}^{2+} / \mathrm{Al}^{3+}$ ratio is shown in Fig. 2.

After ion exchange, two new desorption states were observed at $475 \mathrm{~K}$ and $710 \mathrm{~K}$ for CoZSM5 and at $400 \mathrm{~K}$ and $680 \mathrm{~K}$ for CoY samples. With increasing Co loading, the amount of ammonia desorbing from the strong Brønsted acid sites decreased, while in parallel the concentration of both new desorption states 

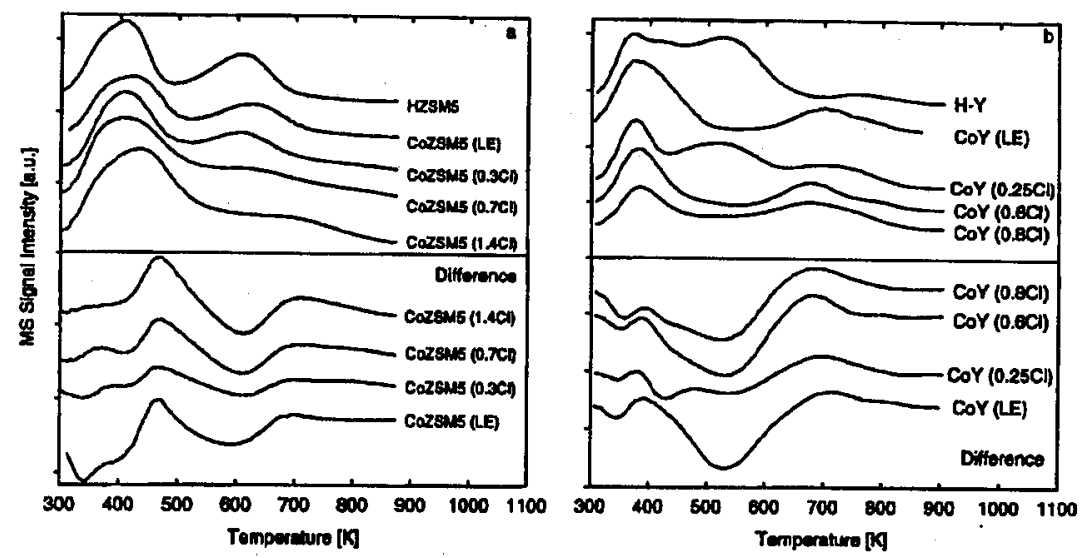

Fig. 1. $\mathrm{NH}_{3}$ t.p.d. of CoZSM5 (a) and $\mathrm{CoY}$ (b) prepared with $\mathrm{CoCl}_{2}$.

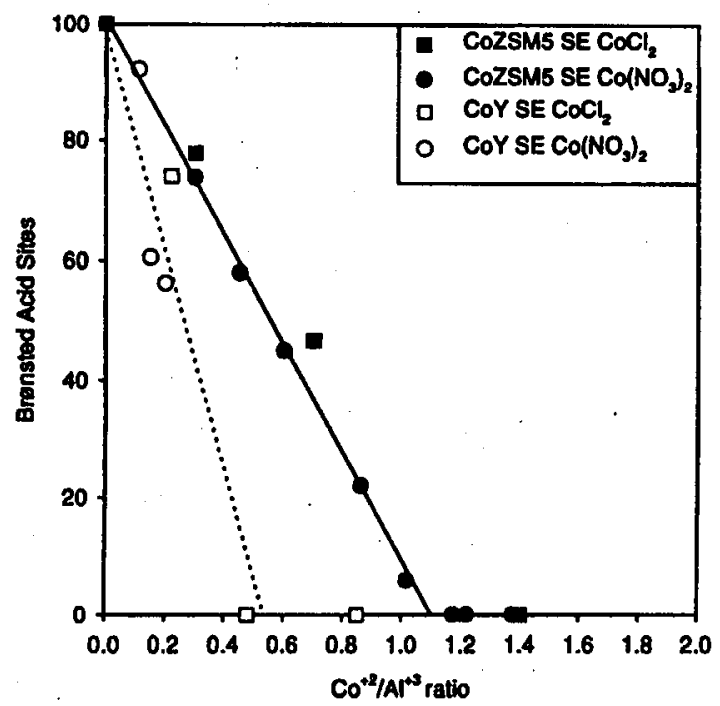

Fig. 2. Concentration of strong Brønsted acid sites as a function of the $\mathrm{Co}^{2+} / \mathrm{Al}^{3+}$ ratio.

increased. After ion exchange strong Brønsted acid sites were observed only on CoY samples with $\mathrm{Co}^{2+} / \mathrm{Al}^{3+}<0.5$ and on CoZSM5 with $\mathrm{Co}^{2+} / \mathrm{Al}^{3+}<1$.

The X-ray absorption near-edge structure (XANES) of the samples after drying at $373 \mathrm{~K}$ is shown in Fig. 3. On samples prepared by ion exchange with $\mathrm{CoCl}_{2}$ the XANES was similar to that of crystalline $\mathrm{CoCl}_{2}$. Especially the single peak close to the absorption edge and the shoulder about $18 \mathrm{eV}$ above the edge were observed for both materials.

The results of the extended X-ray absorption fine structure (EXAFS) analysis are reported in Table. In the first coordination shell only $\mathrm{Co}-\mathrm{Cl}$ neighbors were 


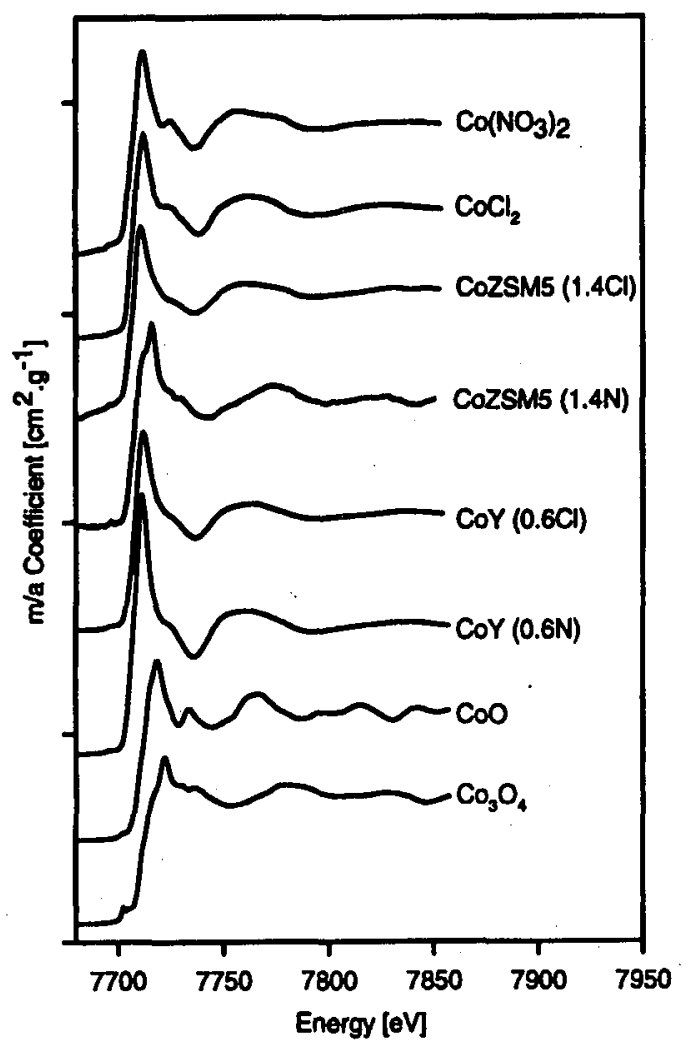

Fig. 3. XANES of the Co containing zeolites.

TABLE

Results of the EXAFS analysis.

\begin{tabular}{c|c|c|c|c}
\hline \hline Sample & Coordination & $N$ & $r[\AA]$ & $\Delta \sigma^{2}\left[\AA^{2}\right]$ \\
\hline $\mathrm{CoCl}_{2}$ Reference & $\mathrm{Co}-\mathrm{Cl}$ & 4 & 1.91 & - \\
$\mathrm{Co}_{3} \mathrm{O}_{4}$ Reference & $\mathrm{Co}-\mathrm{O}$ & 4 & 1.92 & - \\
$\mathrm{CoZSM} 5(\mathrm{LE})$ & $\mathrm{Co}-\mathrm{Cl}$ & 0.8 & 1.87 & $4 \times 10^{-4}$ \\
$\mathrm{CoZSM} 5(1.4 \mathrm{Cl})$ & $\mathrm{Co}-\mathrm{Cl}$ & 0.9 & 1.87 & $1 \times 10^{-4}$ \\
$\mathrm{CoY}(0.6 \mathrm{Cl})$ & $\mathrm{Co}-\mathrm{Cl}$ & 0.8 & 1.86 & $7 \times 10^{-4}$
\end{tabular}

observed. The $\mathrm{Co}-\mathrm{Cl}$ distance, which was somewhat smaller than in crystalline $\mathrm{CoCl}_{2}$ and the coordination number around one indicate that small $\mathrm{Co}-\mathrm{Cl}$ units were present in both samples. XRD of the ion exchanged samples revealed that the structure of the zeolite lattice was not affected by the ion exchange reactions. 


\section{Discussion}

Formally, one $\mathrm{Co}^{2+}$ cation can be exchanged for two protons of each SiOHAl group. Therefore, a complete exchange can be already achieved at a $\mathrm{Co}^{2+} / \mathrm{Al}^{3+}$ ratio of 0.5 . However, with CoZSM5 samples the complete removal of the strong Brønsted acid sites was only observed at $\mathrm{Co}^{2+} / \mathrm{Al}^{3+}$ ratios exceeding one. On samples with lower $\mathrm{Co}^{2+}$ concentrations strong Brønsted acid sites were still observable. Thus, during solid state ion exchange one $\mathrm{Co}^{2+}$ cation was exchanged with only one proton from HZSM5. This indicates that in this zeolite the positions of the tetrahedrally coordinated $\mathrm{Al}^{3+}$ are spatially too much separated in order to compensate their charge with only one $\mathrm{Co}^{2+}$ cation. In the contrary, in CoY samples all strong Brønsted acid sites were already removed at a $\mathrm{Co}^{2+} / \mathrm{Al}^{3+}$ ratio of 0.5 . Therefore, we conclude that on the $\mathrm{CoY}$ samples one $\mathrm{Co}^{2+}$ cation was exchanged for two protons, as expected from the charges of the ions. In these samples, the significant higher $\mathrm{Si} / \mathrm{Al}$ ratio of the zeolite and the larger pores allow one $\mathrm{Co}^{2+}$ to balance the charge of two SiOHAl groups. Note that for both zeolites the stoichiometry of the solid state ion exchange reaction was independent of the $\mathrm{Co}^{2+} / \mathrm{Al}^{3+}$ ratio and the $\mathrm{Co}^{2+}$ source used. Moreover, these results indicate that on CoZSM5 an equimolar $\mathrm{Co}^{2+} / \mathrm{Al}^{3+}$ ratio is preferred over the exchange of one $\mathrm{Co}^{2+}$ cation with two protons even at low $\mathrm{Co}^{2+}$ concentrations. The incorporation of $\mathrm{Co}^{2+}$ resulted in the formation of new acid sites, indicated by two additional desorption states in $\mathrm{NH}_{3}$ t.p.d. Ir spectra of adsorbed pyridine revealed that both sites are of Lewis acid character. These sites are $(\mathrm{CoCl})^{+}$groups, unveiled by the XANES and the analysis of the EXAFS, where $\mathrm{Co}-\mathrm{Cl}$ neighbors were present even after carefully and repeated washing of the samples. We speculate that these $(\mathrm{CoCl})^{+}$species must be strongly stabilized within the zeolite, as they were not hydrolyzed during the washing of the zeolite.

\section{Conclusions}

Ion exchange of Co ions into zeolites leads to the formation of two new Lewis acid sites and to the removal of the Brønsted acid sites. On both types of zeolite, the solid state ion exchange method led to a complete exchange of all protons, if sufficient $\mathrm{Co}^{2+}$ ions were available. On CoZSM5 one proton from the zeolite was exchanged with one $\mathrm{Co}^{2+}$ cation, while on the $\mathrm{CoY}$ samples the stoichiometry of the ion exchange reaction was found to be $\mathrm{Co}^{2+}: \mathrm{Al}^{3+}=1: 2$.

\section{Acknowledgments}

The work was supported by the "Fonds zur Förderung der Wissenschaftlichen Forschung" under project FWF. P9167. X-ray absorption spectra were collected at the National Synchrotron Light Source, Brookhaven National Laboratory, Long Island, USA.

\section{References}

[1] J.A. Martens, P.A. Jacobs, J. Weitkamp, Appl. Catal. 20, 239 (1986).

[2] W.J.J. Welters, G. Vorbeck, H.W. Zandbergen, J.W. de Haan, V.H.J. de Beer, R.A. van Santen, J. Catal. 150, 155 (1994). 
[3] H.W. Kouwenhoven, Adv. Chem. 121, 529 (1973).

[4] Z. Zhang, S.L. Suib, Y. Zhang, W.A. Hines, J.I. Budnick, J. Am. Chem. Soc. 110, 5569 (1988).

[5] T. Inui, D. Medhanavyn, Appl. Catal. 18, 311 (1985).

[6] A.G. Dhere, R.J. De Angelis, P.J. Reucroft, J. Mol. Catal. 20, 301 (1983).

[7] H.G. Karge, H.K. Beyer, G. Borbély, Catalysis Today 3, 41 (1988). 